\title{
DEVELOPMENT AND OPERALISATION OF A SUPPORT PROGRAMME FOR NURSING SERVICE MANAGERS: PART 2
}

\author{
M Poggenpoel and A Gmeiner
}

\section{ABSTRACT}

This paper describes research conducted to develop and implement a support programme for nursing service managers suffering from fatigue. The support programme was developed on the basis of results obtained from a survey that ascertained nursing service managers' views about the problems they were experiencing in their everyday lives.

A multiple case-study design was utilised to describe the operationalisation of the support programme. The sample consisted of forty-eight English speaking and fifty-two Afrikaans speaking nursing service managers from the old Transvaal region (Gauteng, North West and Eastern Transvaal. The support programme was implemented during two one-day workshops, one with the Afrikaans speaking group and one with the English speaking group of nursing service managers. Data were gathered about operationalisation of the support programme through multiple methods: observation, audiotape recordings, written documents and field notes. The data were analysed by utilising the methods of descriptive analysis.

The results of the research were described by means of multiple descriptive case-studies, whereafter a cross-validation report, as described by Yinn (1989:52-57) was utilised to reflect commonalities and differences between the workshops. Conclusions and recommendations were made and limitations discussed

\section{OPSOMMING}

Die doel van hierdie artikel is om die navorsing te beskryf wat ontwikkel is en ' $n$ ondersteuningsprogram te implementeer vir verpleegdiensbestuurders wat uitgeput is. Die ondersteuningsprogram wat ontwikkel is, is gebaseer op die resultate verkry uit die opname waarin verpleegdiensbestuurders se beskouings betreffende probleme wat hulle in hulle daaglikse lewe beleef, bepaal is.

'n Navorsingsontwerp van meervoudige gevallestudies is gebruik om die implementering van die ondersteuningsprogram te beskryf. Die steekproef het bestaan uit agt en veertig Engelssprekende en twee en vyftig Afrikaanssprekende verpleegdiensbestuurders in die ou Transvaal streek (Gauteng, NoordWes en Oos-Transvaal). Die ondersteuningsprogram is geïmplementeer tydens twee eendagwerkwinkels, een met die Afrikaanse groep en een met die Engelse groep verpleegdiensbestuurders. Data aangaande die implementering van die ondersteuningsprogram is op verskeie wyses ingesamel: waarneming, oudiobandopnames, geskrewe dokumente en veldnotas. Die data is geanaliseer deur die gekombineerde metodes van beskrywende analise.

Die resultate van die navorsing is beskryf deur gebruik te maak van meervoudige beskrywende gevallestudies. Daarna is ' $n$ kruisvalideringsverslag, soos besknf deur Yin (1989:52-57), gebruik om die gemeenskaplikhede en verskille tussen die twee werkwinkels uit te lig. Gevolgtrekkings en aanbevelings is gemaak en beperkinge is bespreek.

\section{BACKGROUND, ORIENTATION AND PROBLEM STATEMENT}

During 1994 it became clear to the health service delivery management team of the old Transvaal region (Gauteng, North West and Eastern Transvaal) that nursing service managers in leadership positions were experiencing much strain in their daily work situation and seemed fatigued and stressed. These nursing service managers apparently were challenged to ensure quality health care for all in a rapidly changing South Africa. The problem identified was that if nursing service managers were fatigued and stressed, this would become an obstacle in ensuring the provision of quality health care.

The executive nursing officer of the old Transvaal region requested help in providing a support programme for nursing service managers in this region. Before the support programme could be developed and implemented, it was necessary to identify nursing service managers' views on problems they were experiencing in their everyday lives and to ascertain their specific needs for support (Poggenpoel \& Gmeiner, 1996).

Secondly it was necessary to develop and implement a support programme based on the results about their specific problems and needs. This article describes the development and operationalisation (implementation) of a support programme.

This research adhered to a holistic approach to nursing service managers which viewed the nursing service manager as a spiritual being/individual who functions in an integrated biospychosocial manner to achieve her quest for wholeness. She interacts with her intemal and external environment holistically. She is also an integral part of her family and community (including the health care delivery system). The patterns of interaction between all of the above-mentioned aspects determine her health status (Oral Roberts University, 1990-1992:136-142; Rand Afrikaans University: Department of Nursing Science. 1992:36-41)

Because of this holistic viewpoint, it was firstly necessary to understand nursing service managers' views on the problems they experience in their everyday lives before a 
support programme based on their identified problems and needs could be compiled. Their need as perceived by the health service management team, namely stress control, would not necessarily be appropriate.

\section{RESEARCH OBJECTIVE}

The objective was to describe the development and operationalisation of a support programme based on the identified problems and needs of the nurse managers.

To achieve this objective, the research was conducted in two phases, namely:

- Using the data gathered in phase 1 (Poggenpoel \& Gmeiner, 1996) as the frame of reference to compile a support programme in the form of a workshop which could address the four major themes elicited.

- A multiple, descriptive case-study design where the operationalisation of the support programme was described and reflected in a cross-validation report of the two described case-studies.

\section{RESEARCH DESIGN AND METHOD}

A qualitative, exploratory, descriptive, contextual case-study research design was used (Mouton \& Marais, 1990:43, 44, 121 \& 205; Burns \& Grove, 1993:28-29).

The results from the questionnaire with open-ended questions (Poggenpoel \& Gmeiner, 1995) were utilised as the frame of reference in order to compile a support programme in the form of a workshop which could then address the four major themes that had been elicited. A multiple case-study design (two case-studies) was utilised to describe the operationalisation of the support programme. The two described case-studies were then used to compile a cross-validation report which is presented as the result of this research.

\section{Sample}

The sampling population consisted of nursing service managers (executive officer; chief and senior nursing service managers and chief professional nurses) employed in the old Transvaal region. The criteria for including the above participants in this sample were that they had to be in charge of a nursing service and had to have verbalised a need for support. A purposive sample (Burns \& Grove, 1987:218-219) of forty-eight English speaking and fifty-two Afrikaans speaking senior and chief nursing service managers was included.

a Measures for ensuring trustworthiness Guba's model (in Lincoln \& Guba, 1985:289-331) was utilised to ensure what is referred to as validity, reliability and objectivity by Krefting (in Krefting. 1991:214-222). The four criteria to ensure trustworthiness are: truth value; applicability; consistency, and neutrality

Truth value was ensured by using strategies of credibility, and applicability by applying strategies of transferability. Consistency was ensured by strategies of dependability, and neutrality by strategies of confirmability.
Table 1 summarises the strategies utilised for ensuring trustworthiness.

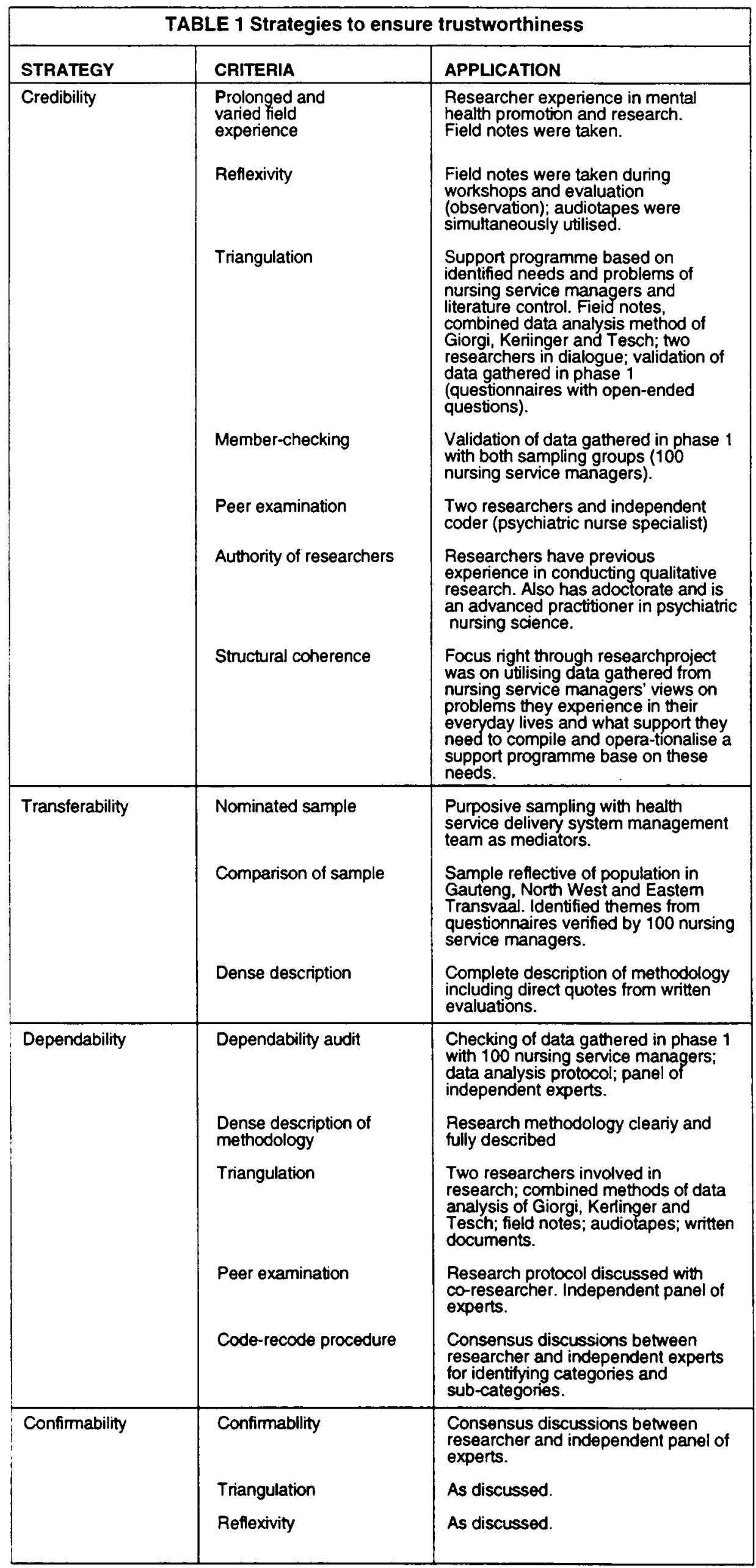


ured by using strategies of credibility, and applicability by applying strategies of transferability. Consistency was ensured by strategies of dependability, and neutrality by strategies of confirmability. Table 1 summarises the strategies utilised for ensuring trustworthiness.

Phase 2: Developing a support programme for nursing service managers

It was clear from the data gathered from the questionnaires (Poggenpoel \& Gmeiner, 1996) that these nursing managers had a need for more/continuous support, especially from their peer group. Peer group support thus had to be the focal point of the workshops/support programme (and not stress management, as the health service delivery management team had indicated previously). The data obtained were analysed by the researcher and a psychiatric nurse with a doctor's degree and experience in qualitative research independently from each other. A protocol indicating guidelines for data analysis was developed, based on the methods of data analysis of Tesch (in Creswell, 1994:155), Giorgi (1985:10-19) and Kerlinger (1986:477 in Poggenpoel \& Gmeiner, 1995).

\section{Data gathering}

From the data gathered and analysed previously (Poggenpoel \& Gmeiner, 1996),

\section{TABLE 2 Nursing service managers' views on problems they experience in their everyday lives Difficulty in relationships with diverse others

$\square$ lear and insecurity related to
the escalating violence
$\square$ resistance to change
$\square$ intimidation and threats to
torce into political activ-
ism/compliance
$\square$ conflict in relationships with
others
$\square$ frustration
$\square$ experience of negative stress

Lack or insufficient

group acceptance/support

口 - insufficient support

口 - effects of insufficient support

a - coping with insufticient support

口 - support needed

Value conflict

口 obedience versus disobedience

orderliness versus disruption

(a) patient centredness versus self-centredness

a acknowledgement of merit versus equality

D punctuality versus tardiness

Difficulty with self-acceptance

- could be better and do better

D - feeling out of control

(Poggenpoel \& Gmeiner, 1986) four major categories/themes were identified. Nursing service managers described the following problems:

- difficulty in relationships with diverse others

- lack of or insufficient group acceptance/support

- value conflicts

- difficulty with self-acceptance

Different sub-categories were identified under the four major categories (see Table 2).

These data were utilised as a frame of reference in order to compile the support programme in the form of two one-day workshops.

\section{$\square$ Data analysis}

The support programme was discussed with an advanced practitioner with a doctor's degree in Psychiatric Nursing -the data were thus verified.

Phase 2: Multiple descriptive case-study, the cross-validation report operationalisation of support programme

A case-study design is a research method that involves intensive exploration and in-depth analysis of a single unit of study - a person, family, group, community or institution - or a very small number of subjects who are examined intensively (Burns \& Grove, 1987:742; Polit \& Hungler, 1989:392; Merriam, 1991:9-10).

The case-study design was utilised in this research to evaluate the operationalisation of the support programme in two workshop groups.

\section{Data gathering}

Multiple sources were utilised in gathering data, namely participant observation (field notes), audiotape recordings, written documents and anonymous evaluations by workshop participants.

\section{Data analysis}

Data analysis was completed by the researcher and a psychiatric nurse with experience in qualitative research working independently from each other. A protocol indicating guidelines for data analysis was developed, based on the methods of Tesch (in Creswell, 1994:155), Giorgi (1985:10-19) and Kerlinger (1986:477). The following steps were completed:

- Data (all data utilised, namely field notes, audiotape recordings, written document and evaluations) was coded by the researchers and independent coders. Coders used bracketing (placing preconceived ideas within brackets) and intuiting (focusing on problems that nursing service managers were experiencing and the support they needed) when going through all the data. They thus gained a sense of the whole (universum).

- Coders identified the major categories represented in the universum.

- Coders then underlined units of meaning that related to the identified major categories.

- The units of meaning were organised into the major categories.

- Sub-categories within the major categories were then identified.

- Relationships amongst major and sub-categories were identified and reflected as themes.

- Consensus discussions between the researchers and independent coders.

One hundred nursing service managers attended the two one-day workshops and completed written evaluations which were then analysed by the researchers and the independent coders. Subsequent consensus discussions took place (Tesch in Creswell, 1994:155).

Two case-studies were compiled based on the data collected from the operationalisation of the support programme in two consecutive workshops with the Afrikaans and English groups of nursing service managers. A cross-validation report, as described by $Y$ in (1989:52-57), was utilised to reflect commonalities and differences between the two workshops.

\section{RESULTS AND DISCUSSION}

The support programme was implemented during two one-day support workshops - one day with forty-eight English speaking participants, and the next day with fifty-two Afrikaans speaking nursing service managers from the old Transvaal region.

\section{Relationship phase}

In both groups the researchers experienced initial mistrust and underlying anger. At first, the reason for this was not clear. In the English group the researchers experienced the group as unsure about the goal of the workshop They could not verbalise their expectations, but one said: "I suppose, expecting to cope with stress."

In the Afrikaans group the researchers experienced even more mistrust, although this group also verified the main themes. This group was very quiet and seemed more negative about being there. Apparently some of them had been "told" to attend the workshop only the day before - it was therefore compulsory. They could not elicit their expectations of the day, but also thought of it as "yet another" stress management workshop. 
Openness developed when the results of the questionnaires were validated with them. It seemed to be a relief that this workshop was not just another stress management workshop, that they were being "heard" and that their needs and problems were being addressed. Thus, establishing a context conducive to learning took some time. The focus was on an experiential approach, where participants could freely ventilate their feelings and reflect on themselves. The group leaders were merely the facilitators during the entire process.

In this phase the two researchers identified that both groups had been told that attending the workshop was compulsory in order to address their "stress".

The groups felt that they had attended numerous stress workshops before - but to no avail. That also explained both groups' initial anger and mistrust. After this had been clarified, the data validated, and the groups assured that this was not a stress management course, active participation started. Participants then realised that the workshop would address their identified problems and needs.

The focus of the workshop was self-experiential exercises where participants could ventilate their feelings of anger and frustration. They could actively work towards utilising and mastering skills and principles to address the major problems and needs they had identified and which were reflected in four major categories, namely: value conflicts; difficulty in relationships with diverse others; difficulty with self-acceptance, and lack of or insufficient group acceptance/support.

Different sub-categories were identified under the four major categories (see Table 2). These were incorporated in compiling the support programme.

\section{口 NURSING SERVICE MANAGERS EXPERIENCE VALUE CONFLICT AS A PROBLEM IN THEIR EVERYDAY LIVES}

The value conflict that nursing service managers experience are: obedience versus disobedience; orderliness versus distuption; patient centredness versus self-centredness, and punctuality versus tardiness. (These are discussed in detail in Poggenpoel \& Gmeiner, 1996.)

The exercise utilised in this category was a values clarification exercise with fifty values listed. It reflects conflicts in different values, namely personal values versus values encountered on the job; personal values versus religious beliefs; how one perceives the work environment versus religious beliefs; how one acts in difficult situations in comparison to how one thinks one ought to act, based on one's beliefs.

After completing the clarification worksheet, participants answered questions related to their scores, namely:
1. How do your personal values compare with the ones you encounter in your work situation? What relationship might there be between the level of correlation between your personal values, your work values and your stress level?

2. How consistent are your personal values with your religious beliefs? What are the primary influences shaping your personal values?

3. How consistent are the values governing nursing practice in your work setting with your religious beliefs? Which values seem most in conflict?

4. How consistent are the values you believe are "most needed as a corrective to problems in your work setting" with your religious beliefs? How can you bring your convictions about the values "most needed as a corrective to problems in your work setting" closer to those beliefs you believe are compatible with your religious beliefs? (Shelley \& Miller, 1991:32-38).

Both groups had great difficulty in completing this exercise. They verbalised that this was a difficult exercise, but acknowledged the reality of conflict in values in their workplace and that this should be addressed continuously in order to avoid conflict. They utilised this stage as a ventilation session.

\section{NURSING SERVICE MANAGERS EXPERIENCE DIFFICULTY IN RELATIONSHIPS WITH DIVERSE OTHERS}

The experience of difficulty in relationships with diverse others refer to: fear and insecurity related to the escalating violence; resistance to change; intimidation and threats to force into political activism/compliance; conflict in relationships with others; frustration, and experience of stress. Each of these sub-categories is discussed in Poggenpoel \& Gmeiner, 1996. (Also see Table 2).

The first exercise utilised in this category focused on stereotyping/cultural diversity (Johnson, 1993:323-324). This exercise aimed at clarifying what stereotypes one has been taught about other groups; what stereotypes they have been taught about you, and how the process of stereotyping works.

On completion of this exercise, participants discussed the following: their personal reactions; how accurate the stereotypes of their identities were - and what feelings were created by the stereotypes of the group they identify with; and what each participant had learnt about stereotyping others.

It was noted that participants were not separated in the Afrikaans group in terms of cultural diversity. They were mixed in terms of culture and race but in the English group. the Whites, Indians and Blacks flocked together according to their respective racial grouping. It was noted that while completing this exercise, a large number of the English participants started smoking, which could have been indicative of high levels of anxiety.

Both groups found this exercise difficult and seemed tired. They could not understand the instruction of the exercise although this was stated clearly and instructions in the workbook also were quite clear.

The following exercise dealt with "labels we don't want" and the exercise presented the opportunity for listening to those in another group and becoming aware of what they had to say. Here again it was noted that both groups had problems in understanding what they were supposed to do. One researcher stated in the field notes that it seemed to her that they were using psychological defense mechanisms in trying to avoid this exercise.

After completion of this exercise, the participants discussed the following: "Do you think awareness can create understanding?" and "How did it feel to stand in front of people and tell them about what you do not like?"

The researchers also included an exercise on negotiating, as differences in culture often calls for negotiation. The goal of this exercise was to improve negotiating effectiveness and skills (Bonoma \& Slevin, 1978:130-133). The participants were relaxed during this exercise, and many of them stated that this could be utilised as a valuable instrument in any future negotiation process on any level

Both groups had difficulty working with people of another race and culture and found the exercise very informative, but tiring. They came to the conclusion that dialogue negotiation and peer group support could indeed contribute to solving this problem.

\section{] NURSING SERVICE MANAGERS EXPERIENCE DIFFICULTY IN SELF-ACCEPTANCE AS A PROBLEM IN THEIR EVERYDAY LIVES}

Two identified sub-categories support this major category, namely could be better and do better and feeling out of control. (These are discussed in Poggenpoel \& Gmeiner, 1996).

The first exercise in this category focused on how self-accepting one is. One way of doing it, is to list all one's assets. If one can list 200 or 300 , then one is very self-accepting Another way is to complete the exercise, which summarised much of the research conducted on self-accepting people (Johnson, 1993:70-71). After completing this exercise, participants discussed the outcome in their smaller groups.

Feedback on this exercise was very positive. Participants spent more time on this exercise and actually asked for extra time to complete it. They all seemed serious and actively involved and appeared concerned about the 
fact that they "worry" too much about things and the mistakes they make, which then influenced their self-acceptance in a negative way.

The exercise on strength building (Johnson, 1993:71-73) also was experienced as positive. The focus of this exercise was to identify each participant's strengths and to determine how these can be used most productively to build personal relationships. The objectives were to increase one's self-acceptance through the increased awareness of strengths and to increase one's awareness of how these strengths can be used to develop fulfilling relationships with self and others.

The climate in both groups was warm and more relaxed than before. Participants shared their strengths with each other and also shared a lot of humour. They were serious when discussing each other's accomplishments and the strengths utilised to achieve these.

The English group stated in their feedback that they found it difficult to list their positive accomplishments and successes, but that they actually felt good when they did it.

The Afrikaans group did not report the same in their feedback, but stated that they also thought it important to be able to give positive feedback to others, as part of being able to accept oneself.

\section{NURSING SERVICE MANAGERS EXPERIENCE A LACK OF OR INSUFFICIENT GROUP ACCEPTANCE AND SUPPORT}

Under this category, nursing service managers identified sources of insufficient support; the effects that insufficient support have on them; how they cope with insufficient support, and what support they needed. (These are discussed in Poggenpoel \& Gmeiner, 1996).

The first exercise utilised in this category concentrated on the level of acceptance in one's own group. The purpose of this exercise was to provide a way in which the level of acceptance in one's own group could be assessed and discussed (Johnson, 1993:209-210). The participants then discussed the results obtained from completing the questionnaire.

They discussed which factors contributed to the present high or low level of acceptance within the group and how the level of acceptance could be increased. The totals of scores added up to the following categories, namely authenticity with me; understanding of me; valuing of me, and accepting of me.

The next exercise focused on each participant's behaviour in her group and it helped participants to reflect on their behaviour within their particular group. The results of this exercise were reflected in a diagram, which is based on the Johari window, namely the "Johnson Trust Diagram" (Johnson, 1993:87-90). The results indicate whether one is trusting or trustworthy, whichever the case may be, or distrustful or untrustworthy, whichever the case may be.

Both groups were actively involved in doing these exercises. For both groups this theme reflected their greatest need, namely more support and more continuous support. They described a real lack of support from members of their peer group and used this session to mobilise additional and more continuous support systems.

\section{Termination phase}

Participants in both workshops gave a written evaluation of the programme, which was based on the following questions:

1. To what extent did you attain the goals of this workshop?

2. How did you experience the group facilitator?

3. What aspects in the group did you experience as positive?

4. What aspects in the group did you experience as less positive?

\section{General comments and suggestions.}

\section{FEEDBACK FROM THE ENGLISH GROUP}

Most of the participants stated that they could reach all the set goals of the day, as one participant stated: "Group objectives were definitely reached in our group - I should say, for myself $100 \% "$. It was found however, that three participants stated exphcitly that there were no set goals for these workshops. This could be interpreted as a form of resistance to active participation in the group: "In our group we found that no goals were spelled out - so we didn't really know".

All the participants experienced the group facilitator as positive and some of the main themes that were elicited were: very friendly and positive, supportive, empathic, humorous, democratic, sensitive, always flexible and taking group needs into account, spontaneous, non-threatening, energetic and professional. One participant said: "She is able to keep the group awake and participative" and another simply evaluated the facilitator as "excellent".

The most positive aspect about the workshop was the participation of all the participants: "We find ourselves to be in the same boat" and "I really enjoyed the interaction of the group". They experienced it as a "togetherness and understanding one another's problems, strengths and weaknesses" and the "sharing of common experiences in interaction with each other". They also stated that they were relieved that this was not just another "stress workshop to no avail" and that the focus was different.

Some exercises were highlighted as very positive, namely "Get to know each other";
"Who am I and where am I going?"; "Stereotype reduction" and the "Negotiation checklist".

In evaluating the less positive aspects in the group, it was noted that participants focused more on external factors, for example participants smoking during sessions; time was a problem (too short); the hall was extremely cold; some felt that they needed more personal attention, and some felt that their groups were too big.

They recommended that such workshops should be implemented on a regular basis: "It was a good workshop and good exercises and it showed that stress can be overcome by more sharing of ideas and experiences" and "we definitely need more of these presentations ... a worthwhile experience".

They also stated that it felt good to ventilate frustrations and "feel relaxed after the day"; "have an emotional breather", and "introspection after the day". All the participants also stated that they reflected on themselves and really "leamed a lot about myself by being honest and open and sharing experiences".

\section{FEEDBACK FROM THE AFRIKAANS GROUP}

All the participants stated that they could attain the set goals and that they could internalise these. Some stated: "We need more practice, however, although our group felt that we did reach all the goals". The participants in the Afrikaans group felt very positive about the workshop and the fact that it was "surprising" and "wonderful" to find the focus of the workshop on their identified needs and problems.

In evaluating the group facilitator, the following themes were elicited: supportive. excellent speaker, friendly, accepting, positive, dynamic, warm, calm, stimulating and democratic. Only one participant stated that "she seems very autocratic and will not give of herself".

The positive aspects that they experienced were the participation of all in getting to know each other better and making new friends; the positive attitude after initial negative foelings; the support they received within the group, and they highlighted the positive experience of the "stereotype reduction" exercise.

They stated that the experience of the day's workshop was very positive and also recommended continuous support groups and workshops. One participant said: "The time was shon. However, we definitely need more of these, even for our subordinates. This is tiring, but very fruitful". Another said: :These type of workshops should be attended by staff on all levels of nursing and presented on a continuous basis". 
They also highlighted the humour in the groups, which made participation easier. They highlighted the fact that their initial negative feelings changed to positive feelings after getting to know each other and discussing common problems and experiences: "We all feel the same about common problems that we all experience".

The less positive aspects again focused on the time aspect: "It was a very valuable day, only the time was too short". Most of the participants commented on the time shortage and therefore stated that workshops of this nature should be repeated on a continuous basis. This group found the stereotype reduction exercise very difficult but informative and also stated that "there must be more explanations of the exercises ... we don't always know what is expected from us".

They recommended a follow-up and more time allocated for such workshops: "I think we should have at least a week workshop". Others said: "This was an eye- opener ... time just flew"; "the day just flew by", and "this is essential and I learned such a lot about myself'. They also said that these workshops were essential in getting acquainted with oneself (self-awareness) and to share and ventilate feelings: "This day made me realise that I' $m$ not alone in my situation ... I feel a lot better".

\section{CONCLUSIONS, LIMITATIONS AND RECOMMENDATIONS}

\section{a Conclusions}

It seems very important to nursing service managers in the health delivery system to be "heard" so that their needs and problems can be taken into account. The health service delivery management team of the old Transvaal region noted that the nursing service managers were experiencing tremendous strain in their daily work situation, but the management team did not really know why or try to establish the reason. The management team contacted the researchers to do "stress management" workshops with the nursing service managers in order to relieve their "stress" and help them to cope better in their daily lives.

The researchers went to the nursing service managers themselves to elicit their views of the problems they were experiencing. Their views of their problems focused on their need for support, especially from their peer group in a similar situation. The nursing managers also felt that at last they were "being heard". One of their greatest needs was the need to be able to reflect on themselves, on their situation and to ventilate feelings of frustration and anger within their peer group.

It is important, therefore, that the health service delivery management team should not indulge in assumptions about the problems of their staff or enforce certain rigid programmes on their staff. The management team should be open and reflective and go to their staff (nursing service managers) to elicit their views of the problems they experience, so that proper help, such as supportive and experiential workshops approach, could be obtained.

\section{Limitations}

- The fact that this workshop was compulsory, made it more difficult for the researchers to gain the trust of the participants and to create a climate conducive to leaming. The relationship phase took much longer than initially anticipated, as mistrust and anger had to be overcome. It should be noted, for the future, that it is important to go to the persons themselves and to elicit their views on what they really need, instead of forcing them to attend workshops, lectures or in-service training.

- Owing to the time limitations there were no follow-up interviews with the participants to evaluate the impact of the programme although they stated in the evaluation that they experienced it as very positive and needed time to internalise what they had reflected on and had done in the workshop sessions.

\section{Recommendations}

- It is recommended that follow-up support workshops should be conducted, as both groups reiterated their strong need for continuous peer group support. Workshops should be conducted with advanced psychiatric nurse practitioners as the group facilitators. These workshops should be conducted at least once a year and, if possible, once every six months.

- Participants stated clearly that they needed more self-reflective workshops and exercises on a continuous basis for total internalisation, for example more strength-building exercises, focus on self-awareness and especially how to deal with cultural diversity. A workshop on stereotyping, where all the aspects of cultural diversity are dealt with, would benefit these nursing service managers.

- Nursing service managers should mobilise peer support groups within their own geographical areas, where they can meet on a regular basis to provide support for each other and reflect on their needs and problems.

\section{$\bullet$}

\section{REFERENCES}

Bonoma, J.V. \& Slevin, D.P. (1978). Executive survival manual. California: Wadsworth Publishing Company.

Burns, N. \& Grove, S.K. (1987). The practice of nursing research: conduct, critique and utilization. Philadelphia: Saunders.
Creswell, J.W. (1994). Research design: qualitative and quantitative approaches. California: Sage.

Hart, L.B. (1980). Learning from conflict - a handbook for trainers and group leaders. California: Mosby.

Johnson, D.W. (1993). Reaching out. Interpersonal effectiveness and self-actualization. Boston: Allyn \& Bacon.

Krefting, L. (1991). Rigor in qualitative research: the assessment of trustworthiness. The American Journal of Occupational Therapy, 45(3), 1991:214-222.

Lincoln, Y.S. \& Guba, E. A. (1985). Naturalistic inquiry. Beverley Hills, California: Sage.

Merriam, S.B. (1991). Case study research in education. A qualitative approach. San Francisco: Jossey-Bass.

Mouton, J. \& Marais, H.C. (1993). Basiese begrippe: metodologie van die geesteswetenskappe. Pretoria: RON.

Polit, D.F. \& Hungler, B.P. (1989). Essentials of nursing esearch: methods, appraisal, and utilization. Philadelphia: Lippincott.

Poggenpoel, M \& Gmeiner, A. (1996). Nursing service managers' views on problems they experience in their everyday lives. Curationis, 19(1): 55-60.

Poggenpoel, M. (1992). Managing change. Nursing RSA 7(a), 1992:28-30.

Poggenpoel, M. (1992). Konflikhantering. Nursing RSA 7(8), 1992:24-26.

Poggenpoel, M. (1992). Doeltreffende konflikhantering. Nursing RSA 7(7), 1992:14-15

Shelley, J.A. \& Miller, A.B. (1991). Values on conflict. Downers Grove, Illinois: Intervarsity Press.

Yinn, R.K. (1989). Case study research, design and methods. Applied social research methods series. Vol. 5. Second edition. London: Sage Publications.

\section{Marie Poggenpoel \\ D.Phil, Professor: Nursing Science RAU \\ Antoinette Gmeiner \\ D.Cur, Lecturer: Nursing Science RAU}

